\title{
Light and Life at Night as Circadian Rhythm Disruptors
}

\author{
Eunil Lee ${ }^{1,2,3}$ and Mari Kim ${ }^{1,4}$ \\ ${ }^{1}$ Department of Preventive Medicine, College of Medicine, Korea University, Seoul, Korea \\ 2Department of Environmental and Global Health, Graduate School of Public Health, Korea University, Seoul, Korea \\ ${ }^{3}$ Program in Public Health, Graduate School, Korea University, Seoul, Korea \\ ${ }^{4}$ Institute of Environmental Health, Korea University, Seoul, Korea
}

Light is an important entraining agent for endogenous circadian rhythms. Artificial light at night (ALAN) negatively influences the circadian system, inducing acute effects on sleep and cognition, as well as chronic endocrine-disrupting effects resulting in obesity, cardiovascular disease, diabetes, and cancer. Although shift workers may be exposed to extreme ALAN, its impact on their health is obscured by factors such as daylight exposure, meal and sleep scheduling, and physical and social behavior. Studies have revealed a significant increase in breast cancer in high ALAN-polluted areas, although the correlation with outdoor or indoor lighting conditions is controversial. Increasing use of electronic devices makes it difficult to assess ALAN exposure in the general population. The development of surrogate markers and critical parameters is crucial for health study by ALAN exposure, and such markers should include risk factors related to ALAN exposure. The present review considers articles investigating the risk of ALAN for shift workers, the general population, and users of electronic devices, and addresses susceptibility factors, including age, sex, and chronotype. Shift workers may be regarded as an extreme ALAN-exposure group, but the growing use of electronic devices and lifestyle changes in the general population make difficult to differentiate ALAN risks to health.

Key Words: Circadian rhythm; Sleep disruption; Cognition; Melatonin; Shift work $\mathrm{nc} / 4.0$ ) which permits unrestricted non-commercial use, distribution, and reproduction in any medium, provided the original work is properly cited.

\section{INTRODUCTION}

The axial rotation of the Earth, together with the light of the sun, generates 24-hour cycles of day and night, and this light-dark cycle is the basis of 24-hour circadian rhythms. Living organisms have their own endogenous circadian rhythms, also with a duration of approximately 24 hours, driven by environmental factors, especially light and darkness [1]. And it is widely known that circadian rhythms of mammals are regulated by an internal biological clock located in the suprachiasmatic nuclei (SCN) situated directly above the optic chiasm [2]. Maintaining the biological clock is crucial for coordinated function throughout the human body because this near-24-hour oscillations are found in essentially every physiological process in the human brain and body $[3,4]$.

The period, phase and amplitude of circadian rhythms can be affected by circadian gene variants, light exposure, social cues, meal times and work schedules [5-8]. Light is the most effective entraining agent for endogenous circadian rhythms and the circadian system is vulnerable to artificial light at night (ALAN). Because of industrialization, urbanization and increase use of electric devices, bright levels of ALAN are expected occasionally and low levels of ALAN are fairly ubiquitous. About 40 lux (lx) of light exposure is common to human and five or more lux is a common exposure level for humans [9]. Satellite images of Earth at night have revealed that ALAN covers $80 \%$ of the planet [10].

Throughout the body, tissue functions are influenced by light, and circadian rhythms are aligned by photoentrainment. Abnormal lighting conditions induce many negative consequences on these rhythms, including both an acute impact on alertness and cognition, and an indirect effect through dysregulation of the circadian system [11]. Exposure to dim light during sleep lead to problems with sleep and cognition $[12,13]$. Exposure to ALAN can also induce broad endocrine effects through direct altering endocrine signal by circadian dyregulation or disrupted melatonin pro- 
duction. Most studies have reported the effects of ALAN on disruption of metabolic processes, resulting in obesity or diabetes and cancer incidence [9]. An increase in cancer has been proposed to be the result of the simultaneous, complex effects of three major mechanisms related to circadian disruption by ALAN: inhibition of melatonin secretion, sleep deprivation and chronodisruption [14]. Furthermore, it has been suggested that ALAN is also associated with a higher risk of cardiovascular disease $[15,16]$ and psychiatric disorders such as depression [17-19].

Evening and night shift workers have a greater risk for exposure to both ALAN and irregular light-dark patterns, and have been shown to be at increased risk for diseases, especially cancer [20]. In 2007, the International Agency for Research on Cancer (IARC) classified "shift work that involves circadian disruption" as a probable human carcinogen, based on limited evidence of carcinogenicity for breast cancer in human studies and sufficient evidence in experimental animals $[19,20]$. Further systemic reviews found insufficient evidence to support an association between night shift work and breast cancer risk [21] and recent review study reported no evidence for a dose relationship between night-shift work and breast cancer risk [22]. This limited evidence associating ALAN with cancer may be related to the lack of a quantitative assessment of ALAN and melatonin levels in human studies [23]. However shift work itself is not an exact proxy for ALAN because the health of shift workers is not only affected directly by ALAN but also by altered exposure to daylight, changes in the timing of daily activities including eating, sleeping, physical activities as well as changes in pattern of social behavior [19]. When evaluating ALAN as a risk factor in human disease, the total exposure patterns to hazardous ALAN and to day light should be assessed, not just ALAN itself [24].

A few epidemiological studies reported a significant associations between ALAN and breast cancer among the general populations in Israel, the state of Georgia in the United States and South Korea [25-27]. These studies all used satellite-measured ALAN levels to determine exposure. However, these levels were not correlated with measured bedroom light levels in evening or nighttime $[28,29]$. And there is only a weak correlation between satellite-measured ALAN and outdoor light levels [28]. These studies suggest that the significant association of ALAN with breast cancer in general population should not be interpreted as a direct ALAN risk in breast cancer. However the satellite-measurements can be a good indication of exposure to ALAN, because it is associated with economic development including the increase use of electricity for working, eating and enjoying leisure time at night [30-32].

The methods of assessment of ALAN exposure were categorized as either outdoor or indoor, based on measuring tools [33]. Outdoor ALAN exposures were typically recorded using satellite data, whereas indoor ALAN exposure was based on individual lighting habits while sleeping and/or indoor illumination levels directly measured by photometer, ActiWatch, $\mathrm{HOBO}$ pendant. The measurements of ALAN should be used alongside personal exposure time to evaluate its circadian disrupting effects. In the study of circadian disruption and disease risk, Figueiro [3] described the urgent need to consider the following: 1) characteristics of light stimulus must be specified including quantity, spectrum, timing, duration and distribution, 2) light stimulus must be measured with calibrated instrument, and 3) daytime light exposures must also be taken into account. The circadian disrupting effects by ALAN should be considered with reference to light exposure during the day, as very little daytime light also dampens human circadian rhythm.

The increase in use of electronic devices makes it more difficult to assess ALAN exposure in people. Humans are almost continuously exposed to unintentional artificial light because of an exponential increase in the use of computers, consoles, tablets, TVs and smartphones [34]. It is possible to monitor the light exposure and circadian-disrupting effects, including changes of melatonin secretion or clock genes, in a small group of people. However, in a large population, it is almost impossible to evaluate long-term circadian disruption caused by a lifetime of ALAN exposure from diverse artificial lighting sources, with differing light intensities and spectrums, duration of exposure and time of day or night. It is necessary to develop surrogate markers and critical parameters for the assessment of ALAN exposure based on experimental studies, such as the exposure scenario techniques used in the study of chemical exposure [35]. In the application of exposure scenario techniques for evaluating ALAN exposure, it is important to fill the gap between the experimental and real world data, to understand the complex interaction between chronodisruption, the suppression of melatonin, and sleep problems, especially in susceptible members of the population, such as children and adolescents $[36,37]$. These markers should include risk behaviors related to ALAN exposure (BALAN). In this review, the important BALAN for shift workers, the general population, and users of electronic devices are addressed, with an emphasis on the need to study how to estimate long-term ALAN exposure based on limited data, by combining BALAN. Circadian disruption resulting from ALAN exposure may be complicated by a change in sleep quality or quantity, variations in meal or exercise time, or genetic factors. However, this review focuses only on ALAN exposure and related behaviors.

\section{METHODS}

The circadian disruptors, ALAN and BALAN, can be classified into three categories based on artificial lighting sources $[19,38]$; the first category is circadian disruption by changing of the daynight cycle, such as in shift work or jet lag. The second category is location of residence, such as urban light pollution, and the third category includes lifestyle choices, such as use of electronic devices at night. By reviewing articles related to ALAN risk for each of these categories, the important behaviors or lifestyle related to exposure to ALAN are considered. In addition, personal susceptibility factors, including age, sex, and chronotype are addressed. 


\section{RESULTS AND DISCUSSION}

\section{Shift workers and jet lag}

Night shift work has become a common occupation: approximately $15 \%$ to $18 \%$ of all workers in Europe and the United States work with night shift schedules [39], and $15 \%$ to $30 \%$ in Korea [40]. Exposure levels of ALAN to shift workers at night were estimated to be from $50 \mathrm{~lx}$ to $100 \mathrm{~lx}$, and sometimes exceeding to $200 \mathrm{~lx}$ [20]. Exposure to ALAN at night leads to melatonin suppression, changes in clock gene expression, and misalignment of sleep [19].

Nocturnal melatonin suppression for different light spectra was plotted based on a mathematical model by Rea et al. [41], who were among the panel members participating in the National Toxicology Program's workshop [19]. The plot showed acute suppression of melatonin following 1 hour exposure of the retina to light, with more efficient suppression induced by daylight than incandescent light [19]. Artificial light inhibits the melatonin levels by about $5 \%$ by $30 \mathrm{~lx}$ exposure, $15 \%$ by $100 \mathrm{~lx}, 35 \%$ by $300 \mathrm{~lx}$, and $55 \%$ by $1,000 \mathrm{~lx}$. Maximum suppression was $70 \%$, following exposure to over 10,000 lx.

Night shift nurses showed significantly lower levels of the melatonin metabolite urinary 6-sulfatoxymelatonin (aMT6s) than dayshift nurses when measured at waking time. However, night shift workers did not show peak melatonin levels while sleeping during the day [42]. The peak melatonin levels occurred during the night among nurses working rotating shifts, and melatonin levels were not different between night and day shift nurses when the nurses experienced ALAN levels below $80 \mathrm{~lx}$ [43]. A reduction in the suppression of melatonin was found among night shift workers, from $40.6 \%$ down to $22.9 \%$, as the number of recent night shifts increased, which suggests a phase shift or adaptation to night work $[20,44]$. Papantoniou et al. [44] also reported that the peak level of melatonin of night shift workers occurred 3 hours later than day-shift workers, and the greater the number of consecutive nights worked, the greater the reduction in aMT6s concentration. Rotating-shift workers also displayed no differences in melatonin levels between night shift and day/evening shift workers, with a possible partial phase shift in their melatonin rhythms [45]. Better health and sleep pattern index scores were reported by air traffic control specialists who preferred rotating schedules and who did not work night shifts than by shift workers [46].

In today's society, the two most common causes of circadian disruption are jet lag and shift work [38]. The changing of lightdark cycles results in circadian misalignment because the light signal is recognized instantaneously by a master pacemaker, the SCN, but peripheral clocks of major organ systems need time to synchronize to new cycles. Shift workers go through a slow adaptation over the course of the week that results in a low nighttime melatonin amplitude [20]. Similarly, humans flying across different time zones also need re-entrainment to a new light-dark cycle, and may suffer "jet lag." Re-entrainment rates are reported to be around $90 \mathrm{~min}$ per day for delayed phase shifts and $60 \mathrm{~min}$ per day for advanced phase shifts $[47,48]$. It takes about 8 days for reentrainment in the case of a 8 hour advanced phase shift, and 5 days for the same length hours of delayed phase shift, based on a computational model of the mammalian circadian clock [49-51].

These findings show that ALAN exposure in shift workers may be highly variable according to work-rotation schedules. A recent cohort study showed no increase in the risk of breast cancer among shift workers compared to the general population, in spite of a significant trend of increased breast cancer cases with average hours of night-work per week [52]. Further studies are needed to determine whether there is an increase of breast cancer in the general population linked to the increased use of electronic devices or a decrease of breast cancer in shift workers given preventive measures, including the rotation of shift schedules. One other possibility may be a decrease in susceptible workers among the shiftworkers, because those who are susceptible do not select shift jobs, or quit early.

About $5 \%$ to $10 \%$ of shift workers complain of sleep or gastrointestinal disturbance. This is called "shift work disorder" and is similar to the symptoms of jet lag [53]. Only some shift-workers experience "shift work disorder," indicating that some shift-workers may be at a greater risk for adverse outcomes related to shift work [38]. Factors predisposing people to poor adaptation to shiftwork include shift schedule, age, gender, chronotype [54-56], physiology [57-59] and genetic differences [60-65]. Increased drowsiness was seen due to sleep deprivation from ALAN which in turn leads to risk of traffic accidents [66]. And sleep deprivation also affects neuroimmune-endocrine axis, which plays an important role in regulating of cell proliferation and immune protection, including the production of cytokines [67-70].

Evaluating the effects of ALAN on circadian disruption in shiftworkers requires careful and complex light exposure assessment, including the intensity and spectrum of the lights, as well as the duration of exposure during both day and night, with a rotating shift schedule. More important considerations in this type of study regard the selection of control subjects, who are already exposed to ALAN in daily life. Personal susceptibility and modifying factors should be included for evaluating the risk of ALAN for shiftworkers. However, this information can only be obtained from small-subject studies. Studying a large number of subjects, would need the development of surrogate markers based on light exposure and related behaviors at day and night, for both shift workers and the general population.

\section{ALAN exposure in the general population}

Exposure to ALAN in the home is significantly associated with both subjective and objective sleep problems in the elderly population [71], while outdoor ALAN is associated with altered sleep behavior in both the general [72] and in elderly [73] population. It has also been shown to be a risk factor for weight gain and the development of obesity in women [74] and general population [75]. Exposure to light at night during sleep, including dim light, may be associated with these sleep and obesity problems, because 
dim light exposure increases the frequency of arousal, and the amount of shallow and REM sleep [12], by disturbing cerebral hemodynamics via the endothelial and autonomic systems, without cortical involvement [76]. A decrease of brain activation while working is also reported after sleeping under $10 \mathrm{~lx}$ light [13]. ALAN also affects learning and memory impairment [77] with increase of neurodegenerataion in Alzheimer's drosophila model [78].

Bright light exposure before bedtime can cause a circadian rhythm shift of cortisol and induces bipolar disorder associated genes [79]. And increase in oxidative stress was found by bright light exposure before bedtime [80] with impaired response inhibition following morning, when evaluated by near-infrared spectroscopy [81]. Evening bright light induces robust melatonin suppression in preschool-age children [36,82]. Room light exposure before bedtime also suppresses melatonin onset and shortens melatonin duration in healthy volunteers [83].

Indoor and outdoor ALAN should be measured together with space-time information to evaluate ALAN exposure in the general population, especially in children. However, it is not possible to gather individual information on space-time ALAN exposure, both indoors and outdoors, for a community based cancer study. Kloog et al. $[25,84,85]$ used satellite photometry or self-reports of bedroom brightness for a breast cancer study. Several subsequent studies found a significant association between breast cancer and satellite ALAN levels $[26,27,86]$. However, critical studies have shown that satellite photometry is not correlated with measured bedroom light levels in the evening or night $[28,29]$ and has only a weak correlation with outdoor light levels [28]. Satellite photometry did not provide enough variability to evaluate the association between melatonin and outdoor ALAN levels [87]. Another problem for satellite-measured LAN being used as proxy for ALAN exposure in the general population is the difference of peak wavelength. In satellite data, the peak wavelength is close to $555 \mathrm{~nm}$ for visual acuity, rather than the $460 \mathrm{~nm}$ spectral sensitivity of the circadian system [88].

Although satellite photometry is not a good surrogate for ALAN exposure in the general population, it may offer an effective representation for the circadian-disrupting effects of urban life. Most people in modern societies live in a built-up environment, which induces circadian disruption because of the absence of suitable light during the day and the presence of light at night, in other words, "dim, extended, aperiodic light exposure" [20]. For this reason, satellite-measured ALAN may be associated with the integrated conditions of urban life, affecting circadian rhythms by low light exposure in the day and high light exposure at night, including room lighting, outdoor lighting and the use of electronic devices. This study may support this hypothesis, because breast cancer risk is associated with satellite photometry, rather than indoor, questionnaire-based ALAN data [89].

\section{Circadian disruption from electronic devices}

Human ALAN exposure has been extended from room and outdoor lighting to the light-emitting screens of many electronic devices. Light from electronic devices can suppress melatonin secretion [90-92], and affect sleep physiology and sleepiness [90,93,94], cognitive performance [95], and mood [96].

A study involving young volunteers demonstrated that exposure to computer screens for 2 hours in the evening significantly disrupted sleep, biological rhythms, and cognitive performance, irrespective of light intensity [34]. Exposure to light-emitting diodes (LED) computer screens has a larger impact than non-LED screen [95]. The peak emission of LEDs is in the blue light range, and they emit twice as much blue light as non-LED display screens. Therefore, exposure to LED screens has a larger effect on the biological clock than white incandescent and compact fluorescent bulbs [37] and may cause photoreceptor damage [97].

Comparing the evening use of smartphones with either blue light-suppression devices or conventional LED displays, use of blue light LED smartphones may negatively influence sleep without significant changes in serum melatonin and cortisol levels [98]. Wearing goggles that block blue light when using a tablet for two hours has been shown to result in higher melatonin levels [92].

The evaluation of ALAN exposure from electronic devices should consider light intensity, including blue light, time of day, and duration of usage. However, it is also important to note that there are a wide range of electronic devices, including televisions, consoles, computers and cell phones. Adolescent exposure to ALAN through the use of electronic devices is not easily distinguishable from other health-risk behaviors, such as media overuse and internet addiction [37]. Late-night cell phone use by adolescents has been associated with a reduction in sleep quality [99]. In the United States, about $74 \%$ of adolescents have internet access at home [100] and excessive mobile phone/internet usage may also lead to sleep disturbances to adolescents [101-104] and adults [105]. Overuse of electronic media is also associated with sedentary behavior at home [106], which presents a cardio-metabolic risk [107]. It is necessary to develop an average mixed-ALAN exposure index, by use of each type electronic device, to estimate the ALAN exposure based on the questionnaire study.

\section{Personal susceptibility}

Acute melatonin suppression by ALAN is influenced by light exposure during the day, inter-individual sensitivity, chronotype, age, and photic history [108-110]. Individual differences in the response of light may be related to individual differences in prior light exposure and/or genetic differences [111]. There is a large inter-individual variation in response to light intensity with highly sensitive individuals even responding to 30 lux exposure [112].

Chronotype has an independent effect to melatonin rhythms affected by rotating-shift work [113]. Associations between chronotype and obesity showed mixed results [114]. Of the 5 articles exploring this link, 3 found a positive association between evening chronotype shift workers and obesity, while 2 studies did not support this relationship. A recent review only addressed a limited number of studies into chronotype and nutrition, and further research is needed [115]. 
The sensitivity of adolescents to ALAN may lead to sleep misalignment with poor sleep quality, and this should be considered a matter of public health [116]. Melatonin levels under standard room lighting conditions (120-140 lx) was suppressed to a higher degree in children than in adults ( $51 \%$ vs. $26 \%$ inhibition, respectively [117]. Increased sensitivity to evening light was found among pre/mid puberty adolescents compared to their late/postpubertal counterparts [118]. Circadian rhythms undergo a gradual loss of amplitude with ageing, and older people generally suffer from less sleep and poorer sleep efficiency $[119,120]$. However, young adults appeared more vulnerable to chronic sleep deficiency than older adults [121]. This result suggest that exposure to ALAN for young adults should be a cause of concern.

Men show a strong response to blue light in the late evening, even at very low light levels, compared to women [122]. However, female health is known to be susceptible to the impact of desynchronizing work schedules [123] and nighttime impairment in cognitive performance is greater in women than in men [124]. Sex differences in SCN electrical activity suggests that female might be able to phase shift more readily than males, thus resetting to environmental cues [125]. Disruption of circadian rhythms and increase of oxidative stress were more commonly found in female volunteers than in males in the study of bright exposure before bedtime [80].

Selecting or classifying susceptible populations is very important for identifying health risks from any hazard, because the susceptible population may have a different risk to the same exposure compared to the general population. Age and sex are very important modifying variables in relation to ALAN exposure, and are easy to measure by questionnaire. Chronotype can also can be determined by questionnaire, however the high sensitivity to evening light exposure would require further studies for proper evaluation.

\section{CONCLUSION}

To improve the assessment of ALAN exposure as a circadian disruptor, it is necessary to use wearable monitoring devices that measure light intensity in conjunction with the time of day and eating and sleeping behavior. The development of a questionnaire to assess light exposure, including social life and activities during the day and night, is also required [19]. For the evaluation of the health risks caused by ALAN exposure in a large group of subjects, it is necessary to develop surrogate markers to represent ALAN exposure and related behaviors, including shift work, room lighting, outdoor lighting, and the use of electronic devices during the day and night. To develop parameters of risk assessment based on exposure scenario methodology, we need to perform more experimental studies, including animal and human intervention studies as well as small cohort studies, for detailed monitoring of ALAN exposure from various lighting sources, including the use of personal electronic devices.

\section{Acknowledgments}

This research was supported by Korea Environment Industry \& Technology Institute (KEITI) through Environmental Health Action Program, funded by Korea Ministry of Environment (MOE) (No. 2016001360007, No.2017001360006).

\section{Conflicts of Interest}

The authors have no potential conflicts of interest to disclose.

\section{Author Contributions}

Eunil Lee: participated in the conceptualization and design of the study and paper collection, and drafted the paper. Mari Kim: participated in design of the study, review and editing drafts of the paper with writing some of the paper.

\section{ORCID iD}

Eunil Lee (1)

https://orcid.org/0000-0003-1524-5046

\section{REFERENCES}

1. Turek FW. Circadian clocks: not your grandfather's clock. Science 2016; 354:992-993.

2. Bernard S, Gonze D, Čajavec B, Herzel H, Kramer A. Synchronization-induced rhythmicity of circadian oscillators in the suprachiasmatic nucleus. PLoS Comput Biol 2007;3:e68.

3. Figueiro MG. Disruption of circadian rhythms by light during day and night. Curr Sleep Med Rep 2017;3:76-84.

4. Reppert SM, Weaver DR. Coordination of circadian timing in mammals. Nature 2002;418:935-941.

5. Hsu PK, Ptáček LJ, Fu YH. Genetics of human sleep behavioral phenotypes. Methods Enzymol 2015;552:309-324.

6. Roenneberg T, Merrow M. Entrainment of the human circadian clock. Cold Spring Harb Symp Quant Biol 2007;72:293-299.

7. Foster RG, Peirson SN, Wulff K, Winnebeck E, Vetter C, Roenneberg T. Sleep and circadian rhythm disruption in social jetlag and mental illness. Prog Mol Biol Transl Sci 2013;119:325-346.

8. Logan RW, McClung CA. Rhythms of life: circadian disruption and brain disorders across the lifespan. Nat Rev Neurosci 2019;20:49-65.

9. Russart KLG, Nelson RJ. Light at night as an environmental endocrine disruptor. Physiol Behav 2018;190:82-89.

10. Falchi F, Cinzano P, Duriscoe D, Kyba CC, Elvidge CD, Baugh K, et al. The new world atlas of artificial night sky brightness. Sci Adv 2016;2:e1600377.

11. Rupp AC, Ren M, Altimus CM, Fernandez DC, Richardson M, Turek F, et al. Distinct ipRGC subpopulations mediate light's acute and circadian effects on body temperature and sleep. eLife 2019;8:e44358.

12. Cho CH, Lee HJ, Yoon HK, Kang SG, Bok KN, Jung KY, et al. Exposure to dim artificial light at night increases REM sleep and awakenings in humans. Chronobiol Int 2016;33:117-123.

13. Kang SG, Yoon HK, Cho CH, Kwon S, Kang J, Park YM, et al. Decrease in fMRI brain activation during working memory performed after sleeping under 10 lux light. Sci Rep 2016;6:36731.

14. Touitou Y, Reinberg A, Touitou D. Association between light at night, melatonin secretion, sleep deprivation, and the internal clock: health impacts and mechanisms of circadian disruption. Life Sci 2017;173:94-106.

15. Chellappa SL, Lasauskaite R, Cajochen C. In a heartbeat: light and cardiovascular physiology. Front Neurol 2017;8:541.

16. Morris CJ, Purvis TE, Hu K, Scheer FA. Circadian misalignment increases cardiovascular disease risk factors in humans. Proc Natl Acad Sci USA 2016; 113:E1402-E1411.

17. Bedrosian TA, Nelson RJ. Timing of light exposure affects mood and brain circuits. Transl Psychiatry 2017;7:e1017.

18. Wright KP Jr, Bogan RK, Wyatt JK. Shift work and the assessment and 
management of shift work disorder (SWD). Sleep Med Rev 2013;17:41-54.

19. Lunn RM, Blask DE, Coogan AN, Figueiro MG, Gorman MR, Hall JE, et al. Health consequences of electric lighting practices in the modern world: a report on the National Toxicology Program's workshop on shift work at night, artificial light at night, and circadian disruption. Sci Total Environ 2017;607-608:1073-1084.

20. Hunter CM, Figueiro MG. Measuring light at night and melatonin levels in shift workers: a review of the literature. Biol Res Nurs 2017;19:365-374.

21. Kolstad HA. Nightshift work and risk of breast cancer and other cancers--a critical review of the epidemiologic evidence. Scand J Work Environ Health 2008;34:5-22.

22. Kamdar BB, Tergas AI, Mateen FJ, Bhayani NH, Oh J. Night-shift work and risk of breast cancer: a systematic review and meta-analysis. Breast Cancer Res Treat 2013;138:291-301.

23. Ijaz S, Verbeek J, Seidler A, Lindbohm ML, Ojajarvi A, Orsini N, et al. Nightshift work and breast cancer--a systematic review and meta-analysis. Scand J Work Environ Health 2013;39:431-447.

24. Keshet-Sitton A, Or-Chen K, Yitzhak S, Tzabary I, Haim A. Light and the city: breast cancer risk factors differ between urban and rural women in Israel. Integr Cancer Ther 2017;16:176-187.

25. Kloog I, Haim A, Stevens RG, Barchana M, Portnov BA. Light at night codistributes with incident breast but not lung cancer in the female population of Israel. Chronobiol Int 2008;25:65-81.

26. Bauer SE, Wagner SE, Burch J, Bayakly R, Vena JE. A case-referent study: light at night and breast cancer risk in Georgia. Int J Health Geogr 2013; 12:23.

27. Kim YJ, Lee E, Lee HS, Kim M, Park MS. High prevalence of breast cancer in light polluted areas in urban and rural regions of South Korea: an ecologic study on the treatment prevalence of female cancers based on National Health Insurance data. Chronobiol Int 2015;32:657-667.

28. Huss A, van Wel L, Bogaards L, Vrijkotte T, Wolf L, Hoek G, et al. Shedding some light in the Dark-A comparison of personal measurements with satellite-based estimates of exposure to light at night among children in the Netherlands. Environ Health Perspect 2019;127:67001.

29. Rea MS, Brons JA, Figueiro MG. Measurements of light at night (LAN) for a sample of female school teachers. Chronobiol Int 2011;28:673-680.

30. Ghosh T, Anderson S, Elvidge C, Sutton P. Using nighttime satellite imagery as a proxy measure of human well-being. Sustainability 2013;5:49885019 .

31. Stevens RG, Zhu Y. Electric light, particularly at night, disrupts human circadian rhythmicity: is that a problem? Philos Trans R Soc Lond B Biol Sc 2015;370:20140120

32. Stevens RG. Artificial lighting in the industrialized world: circadian disruption and breast cancer. Cancer Causes Control 2006;17:501-507.

33. Cho Y, Ryu SH, Lee BR, Kim KH, Lee E, Choi J. Effects of artificial light at night on human health: a literature review of observational and experimental studies applied to exposure assessment. Chronobiol Int 2015;32: 1294-1310.

34. Green A, Cohen-Zion M, Haim A, Dagan Y. Evening light exposure to computer screens disrupts human sleep, biological rhythms, and attention abilities. Chronobiol Int 2017;34:855-865.

35. Taxell P, Koponen M, Kallio N, Santonen T. Consolidating exposure scenario information for mixtures--experiences and challenges. Ann Occup Hyg 2014;58:793-805.

36. Akacem LD, Wright KP Jr, LeBourgeois MK. Sensitivity of the circadian system to evening bright light in preschool-age children. Physiol Rep 2018; 6:e13617.

37. Touitou Y, Touitou D, Reinberg A. Disruption of adolescents' circadian clock: the vicious circle of media use, exposure to light at night, sleep loss and risk behaviors. J Physiol Paris 2016;110(4 Pt B):467-479.

38. Reid KJ, Abbott SM. Jet lag and shift work disorder. Sleep Med Clin 2015; 10:523-535.

39. Straif K, Baan R, Grosse Y, Secretan B, El Ghissassi F, Bouvard V, et al. Carcinogenicity of shift-work, painting, and fire-fighting. Lancet Oncol 2007;8: 1065-1066.

40. Park TJ, Paek DM, Joh KO, Park JS, Cho Si. The relationship between shift work and work-related injuries among Korean Workers. Korean J Occup Environ Med 2012;24:52-60.

41. Rea MS, Figueiro MG, Bullough JD, Bierman A. A model of phototrans- duction by the human circadian system. Brain Res Brain Res Rev 2005;50: 213-228.

42. Grundy A, Sanchez M, Richardson H, Tranmer J, Borugian M, Graham $\mathrm{CH}$, et al. Light intensity exposure, sleep duration, physical activity, and biomarkers of melatonin among rotating shift nurses. Chronobiol Int 2009; 26:1443-1461.

43. Grundy A, Tranmer J, Richardson H, Graham CH, Aronson KJ. The influence of light at night exposure on melatonin levels among Canadian rotating shift nurses. Cancer Epidemiol Biomark Prev 2011;20:2404-2412.

44. Papantoniou K, Pozo OJ, Espinosa A, Marcos J, Castaño-Vinyals G, Basagaña $\mathrm{X}$, et al. Circadian variation of melatonin, light exposure, and diurnal preference in day and night shift workers of both sexes. Cancer Epidemiol Biomarkers Prev 2014;23:1176-1186.

45. Dumont M, Lanctot V, Cadieux-Viau R, Paquet J. Melatonin production and light exposure of rotating night workers. Chronobiol Int 2012;29:203210.

46. Cruz C, Della Rocco P, Hackworth C. Effects of quick rotating shift schedules on the health and adjustment of air traffic controllers. Aviat Space Environ Med 2000;71:400-407.

47. Boulos Z, Campbell SS, Lewy AJ, Terman M, Dijk DJ, Eastman CI. Light treatment for sleep disorders: consensus report. VII. Jet lag. J Biol Rhythms 1995;10:167-176.

48. Aschoff J, Hoffmann K, Pohl H, Wever R. Re-entrainment of circadian rhythms after phase-shifts of the Zeitgeber. Chronobiologia 1975;2:23-78.

49. Leloup JC, Goldbeter A. Critical phase shifts slow down circadian clock recovery: implications for jet lag. J Theor Biol 2013;333:47-57.

50. Leloup JC, Goldbeter A. Toward a detailed computational model for the mammalian circadian clock. Proc Natl Acad Sci USA 2003;100:7051-7056.

51. Leloup JC, Goldbeter A. Modeling the mammalian circadian clock: sensitivity analysis and multiplicity of oscillatory mechanisms. J Theor Biol 2004; 230:541-562.

52. Jones ME, Schoemaker MJ, McFadden EC, Wright LB, Johns LE, Swerdlow AJ. Night shift work and risk of breast cancer in women: the Generations Study cohort. Br J Cancer 2019;121:172-179.

53. Drake CL, Roehrs T, Richardson G, Walsh JK, Roth T. Shift work sleep disorder: prevalence and consequences beyond that of symptomatic day workers. Sleep 2004;27:1453-1462.

54. Folkard S, Monk TH, Lobban MC. Short and long-term adjustment of circadian rhythms in 'permanent' night nurses. Ergonomics 1978;21:785-799.

55. Harma MI, Hakola T, Akerstedt T, Laitinen JT. Age and adjustment to night work. Occup Environ Med 1994;51:568-573.

56. Smith L, Mason C. Age and the subjective experience of shiftwork. J Hum Ergol (Tokyo) 2001;30:307-313

57. Gumenyuk V, Howard R, Roth T, Korzyukov O, Drake CL. Sleep loss, circadian mismatch, and abnormalities in reorienting of attention in night workers with shift work disorder. Sleep 2014;37:545-556.

58. Gumenyuk V, Roth T, Drake CL. Circadian phase, sleepiness, and light exposure assessment in night workers with and without shift work disorder. Chronobiol Int 2012;29:928-936.

59. Gumenyuk V, Roth T, Korzyukov O, Jefferson C, Kick A, Spear L, et al. Shift work sleep disorder is associated with an attenuated brain response of sensory memory and an increased brain response to novelty: an ERP study. Sleep 2010;33:703-713.

60. Gumenyuk V, Belcher R, Drake CL, Roth T. Differential sleep, sleepiness, and neurophysiology in the insomnia phenotypes of shift work disorder. Sleep 2015;38:119-126.

61. Archer SN, Carpen JD, Gibson M, Lim GH, Johnston JD, Skene DJ, et al. Polymorphism in the PER3 promoter associates with diurnal preference and delayed sleep phase disorder. Sleep 2010;33:695-701.

62. Archer SN, Robilliard DL, Skene DJ, Smits M, Williams A, Arendt J, et al. A length polymorphism in the circadian clock gene Per3 is linked to delayed sleep phase syndrome and extreme diurnal preference. Sleep 2003;26: 413-415.

63. Ebisawa T, Uchiyama M, Kajimura N, Mishima K, Kamei Y, Katoh M, et al. Association of structural polymorphisms in the human period 3 gene with delayed sleep phase syndrome. EMBO Rep 2001;2:342-346.

64. Goel N, Banks S, Mignot E, Dinges DF. PER3 polymorphism predicts cumulative sleep homeostatic but not neurobehavioral changes to chronic partial sleep deprivation. PLoS One 2009;4:e5874. 
65. Viola AU, Archer SN, James LM, Groeger JA, Lo JC, Skene DJ, et al. PER3 polymorphism predicts sleep structure and waking performance. Curr Biol 2007;17:613-618

66. Nakata A. Effects of long work hours and poor sleep characteristics on workplace injury among full-time male employees of small- and mediumscale businesses. J Sleep Res 2011;20:576-584.

67. Everson CA, Henchen CJ, Szabo A, Hogg N. Cell injury and repair resulting from sleep loss and sleep recovery in laboratory rats. Sleep 2014;37:19291940.

68. Dimitrov S, Lange T, Tieken S, Fehm HL, Born J. Sleep associated regulation of T helper 1/T helper 2 cytokine balance in humans. Brain Behav Immun 2004;18:341-348.

69. Lange T, Dimitrov S, Born J. Effects of sleep and circadian rhythm on the human immune system. Ann N Y Acad Sci 2010;1193:48-59.

70. Haus EL, Smolensky MH. Shift work and cancer risk: potential mechanistic roles of circadian disruption, light at night, and sleep deprivation. Sleep Med Rev 2013;17:273-284.

71. Obayashi K, Saeki K, Kurumatani N. Association between light exposure at night and insomnia in the general elderly population: the HEIJO-KYO cohort. Chronobiol Int 2014;31:976-982.

72. Ohayon MM, Milesi C. Artificial outdoor nighttime lights associate with altered sleep behavior in the American general population. Sleep 2016;39: 1311-1320.

73. Min JY, Min KB. Outdoor artificial nighttime light and use of hypnotic medications in older adults: a population-based cohort study. J Clin Sleep Med 2018;14:1903-1910.

74. Park YM, White AJ, Jackson CL, Weinberg CR, Sandler DP. Association of exposure to artificial light at night while sleeping with risk of obesity in women. JAMA Intern Med 2019;179:1061-1071.

75. Koo YS, Song JY, Joo EY, Lee HJ, Lee E, Lee SK, et al. Outdoor artificial light at night, obesity, and sleep health: cross-sectional analysis in the KoGES study. Chronobiol Int 2016;33:301-314.

76. Kim TJ, Lee BU, Sunwoo JS, Byun JI, Moon J, Lee ST, et al. The effect of dim light at night on cerebral hemodynamic oscillations during sleep: a nearinfrared spectroscopy study. Chronobiol Int 2017;34:1325-1338.

77. Fonken LK, Kitsmiller E, Smale L, Nelson RJ. Dim nighttime light impairs cognition and provokes depressive-like responses in a diurnal rodent. J Biol Rhythms 2012;27:319-327.

78. Kim M, Subramanian M, Cho YH, Kim GH, Lee E, Park JJ. Short-term exposure to dim light at night disrupts rhythmic behaviors and causes neurodegeneration in fly models of tauopathy and Alzheimer's disease. Biochem Biophys Res Commun 2018;495:1722-1729.

79. Cho CH, Moon JH, Yoon HK, Kang SG, Geum D, Son GH, et al. Molecular circadian rhythm shift due to bright light exposure before bedtime is related to subthreshold bipolarity. Sci Rep 2016;6:31846.

80. Lee HS, Lee E, Moon JH, Kim Y, Lee HJ. Circadian disruption and increase of oxidative stress in male and female volunteers after bright light exposure before bed time. Mol Cell Toxicol 2019;15:221-229.

81. Byun JI, Lee BU, Koo YS, Sunwoo JS, Lim JA, Moon J, et al. Bright light exposure before bedtime impairs response inhibition the following morning: a non-randomized crossover study. Chronobiol Int 2018;35:1035-1044.

82. Akacem LD, Wright KP Jr, LeBourgeois MK. Bedtime and evening light exposure influence circadian timing in preschool-age children: a field study. Neurobiol Sleep Circadian Rhythms 2016;1:27-31.

83. Gooley JJ, Chamberlain K, Smith KA, Khalsa SB, Rajaratnam SM, Van Reen $\mathrm{E}$, et al. Exposure to room light before bedtime suppresses melatonin onset and shortens melatonin duration in humans. J Clin Endocrinol Metab 2011; 96:E463-E472.

84. Kloog I, Stevens RG, Haim A, Portnov BA. Nighttime light level co-distributes with breast cancer incidence worldwide. Cancer Causes Control 2010;21:2059-2068.

85. Kloog I, Portnov BA, Rennert HS, Haim A. Does the modern urbanized sleeping habitat pose a breast cancer risk? Chronobiol Int 2011;28:76-80.

86. Kim YJ, Park MS, Lee E, Choi JW. High incidence of breast cancer in lightpolluted areas with spatial effects in Korea. Asian Pac J Cancer Prev 2016;17: 361-367.

87. Hurley S, Nelson DO, Garcia E, Gunier R, Hertz A, Reynolds P. A crosssectional analysis of light at night, neighborhood sociodemographics and urinary 6-sulfatoxymelatonin concentrations: implications for the conduct of health studies. Int J Health Geogr 2013;12:39.

88. Brainard GC, Hanifin JP, Greeson JM, Byrne B, Glickman G, Gerner E, et al. Action spectrum for melatonin regulation in humans: evidence for a novel circadian photoreceptor. J Neurosci 2001;21:6405-6412.

89. Hurley S, Goldberg D, Nelson D, Hertz A, Horn-Ross PL, Bernstein L, et al. Light at night and breast cancer risk among California teachers. Epidemiology 2014;25:697-706.

90. Chang AM, Aeschbach D, Duffy JF, Czeisler CA. Evening use of light-emitting eReaders negatively affects sleep, circadian timing, and next-morning alertness. Proc Natl Acad Sci USA 2015;112:1232-1137.

91. Figueiro MG, Wood B, Plitnick B, Rea MS. The impact of light from computer monitors on melatonin levels in college students. Neuro Endocrinol Lett 2011;32:158-163.

92. Wood B, Rea MS, Plitnick B, Figueiro MG. Light level and duration of exposure determine the impact of self-luminous tablets on melatonin suppression. Appl Ergon 2013;44:237-240.

93. Grønli J, Byrkjedal IK, Bjorvatn B, Nodtvedt O, Hamre B, Pallesen S. Reading from an iPad or from a book in bed: the impact on human sleep. A randomized controlled crossover trial. Sleep Med 2016;21:86-92.

94. Higuchi S, Motohashi Y, Liu Y, Maeda A. Effects of playing a computer game using a bright display on presleep physiological variables, sleep latency, slow wave sleep and REM sleep. J Sleep Res 2005;14:267-273.

95. Cajochen C, Frey S, Anders D, Spati J, Bues M, Pross A, et al. Evening exposure to a light-emitting diodes (LED)-backlit computer screen affects circadian physiology and cognitive performance. J Appl Physiol (1985) 2011;110: 1432-1438.

96. Sroykham W, Wongsawat Y. Effects of LED-backlit computer screen and emotional selfregulation on human melatonin production. Conf Proc IEEE Eng Med Biol Soc 2013;2013:1704-1707.

97. Tosini G, Ferguson I, Tsubota K. Effects of blue light on the circadian system and eye physiology. Mol Vis 2016;22:61-72.

98. Heo JY, Kim K, Fava M, Mischoulon D, Papakostas GI, Kim MJ, et al. Effects of smartphone use with and without blue light at night in healthy adults: a randomized, double-blind, cross-over, placebo-controlled comparison. J Psychiatr Res 2017;87:61-70.

99. Amra B, Shahsavari A, Shayan-Moghadam R, Mirheli O, Moradi-Khaniabadi B, Bazukar M, et al. The association of sleep and late-night cell phone use among adolescents. J Pediatr (Rio J) 2017;93:560-567.

100. Van den Bulck J. The effects of media on sleep. Adolesc Med State Art Rev 2010;21:418-429.

101. Calamaro CJ, Mason TB, Ratcliffe SJ. Adolescents living the 24/7 lifestyle: effects of caffeine and technology on sleep duration and daytime functioning. Pediatrics 2009;123:e1005-e1010.

102. Pea R, Nass C, Meheula L, Rance M, Kumar A, Bamford H, et al. Media use, face-to-face communication, media multitasking, and social well-being among 8- to 12-year-old girls. Dev Psychol 2012;48:327-336.

103. Van den Bulck J. Text messaging as a cause of sleep interruption in adolescents, evidence from a cross-sectional study. J Sleep Res 2003;12:263.

104. de Seze R, Ayoub J, Peray P, Miro L, Touitou Y. Evaluation in humans of the effects of radiocellular telephones on the circadian patterns of melatonin secretion, a chronobiological rhythm marker. J Pineal Res 1999;27:237-242.

105. Exelmans L, Van den Bulck J. Bedtime mobile phone use and sleep in adults. Soc Sci Med 2016;148:93-101.

106. Granich J, Rosenberg M, Knuiman MW, Timperio A. Individual, social, and physical environment factors associated with electronic media use among children: sedentary behavior at home. J Phys Act Health 2011;8: 613-625.

107. Owen N, Sparling PB, Healy GN, Dunstan DW, Matthews CE. Sedentary behavior: emerging evidence for a new health risk. Mayo Clin Proc 2010; 85:1138-1141.

108. Chang AM, Scheer FA, Czeisler CA. The human circadian system adapts to prior photic history. J Physiol 2011;589(Pt 5):1095-1102.

109. Glickman G, Webb IC, Elliott JA, Baltazar RM, Reale ME, Lehman MN, et al. Photic sensitivity for circadian response to light varies with photoperiod. J Biol Rhythms 2012;27:308-318.

110. Hébert M, Martin SK, Lee C, Eastman CI. The effects of prior light history on the suppression of melatonin by light in humans. J Pineal Res 2002; 33:198-203.

111. Santhi N, Thorne HC, van der Veen DR, Johnsen S, Mills SL, Hommes V, 
et al. The spectral composition of evening light and individual differences in the suppression of melatonin and delay of sleep in humans. J Pineal Res 2012;53:47-59.

112. Phillips AJK, Vidafar P, Burns AC, McGlashan EM, Anderson C, Rajaratnam SMW, et al. High sensitivity and interindividual variability in the response of the human circadian system to evening light. Proc Natl Acad Sci USA. 2019;116:12019-12024.

113. Razavi P, Devore EE, Bajaj A, Lockley SW, Figueiro MG, Ricchiuti V, et al. Shift work, chronotype, and melatonin rhythm in nurses. Cancer Epidemiol Biomarkers Prev 2019;28:1177-1186.

114. Hittle BM, Gillespie GL. Identifying shift worker chronotype: implications for health. Ind Health 2018;56:512-523.

115. Almoosawi S, Vingeliene S, Gachon F, Voortman T, Palla L, Johnston JD, et al. Chronotype: implications for epidemiologic studies on chrono-nutrition and cardiometabolic health. Adv Nutr 2019;10:30-42.

116. Touitou Y. Adolescent sleep misalignment: a chronic jet lag and a matter of public health. J Physiol Paris 2013;107:323-326.

117. Higuchi S, Nagafuchi Y, Lee SI, Harada T. Influence of light at night on melatonin suppression in children. J Clin Endocrinol Metab 2014;99:32983303.
118. Crowley SJ, Cain SW, Burns AC, Acebo C, Carskadon MA. Increased sensitivity of the circadian system to light in early/mid-puberty. J Clin Endocrinol Metab 2015;100:4067-4073.

119. Feinsilver SH, Hernandez AB. Sleep in the elderly: unanswered questions. Clin Geriatr Med 2017;33:579-596.

120. Mattis J, Sehgal A. Circadian rhythms, sleep, and disorders of aging. Trends Endocrinol Metab 2016;27:192-203.

121. Zitting KM, Münch MY, Cain SW, Wang W, Wong A, Ronda JM, et al. Young adults are more vulnerable to chronic sleep deficiency and recurrent circadian disruption than older adults. Sci Rep 2018;8:11052.

122. Chellappa SL, Steiner R, Oelhafen P, Cajochen C. Sex differences in light sensitivity impact on brightness perception, vigilant attention and sleep in humans. Sci Rep 2017;7:14215.

123. Mahoney MM. Shift work, jet lag, and female reproduction. Int J Endocrinol 2010;2010:813764.

124. Santhi N, Lazar AS, McCabe PJ, Lo JC, Groeger JA, Dijk DJ. Sex differences in the circadian regulation of sleep and waking cognition in humans. Proc Natl Acad Sci USA 2016;113:E2730-E2739.

125. Bailey M, Silver R. Sex differences in circadian timing systems: implications for disease. Front Neuroendocrinol 2014;35:111-139. 